\section{Vinayak Nagaraja, MD \\ Department of Cardiovascular Medicine \\ Heart, Vascular, and Thoracic Institute, \\ Divyanshu Mohananey, MD \\ Division of Cardiovascular Medicine, \\ Medical College of Wisconsin}

Cleveland Clinic
Jose Navia, MD

Departments of Thoracic and Cardiovascular Surgery, and Biomedical Engineering,

Cleveland Clinic Florida - Weston
Serge C. Harb, MD

Department of Cardiovascular Medicine, Heart, Vascular, and Thoracic Institute, Cleveland Clinic
Rhonda Miyasaka, MD Department of Cardiovascular Medicine, Heart, Vascular, and Thoracic Institute, Cleveland Clinic
Amar Krishnaswamy, MD Department of Cardiovascular Medicine, Heart, Vascular, and Thoracic Institute, Cleveland Clinic
Samir Kapadia, MD

Department of Cardiovascular Medicine, Heart, Vascular, and Thoracic Institute, Cleveland Clinic

\title{
Functional tricuspid regurgitation: Feasibility of transcatheter interventions
}

\section{ABSTRACT}

Functional tricuspid regurgitation (TR) develops secondary to annular dilation and leaflet tethering as a result of right ventricular remodeling. Invasive surgery for isolated TR is rarely performed due to high inpatient mortality. Transcatheter tricuspid valve intervention is an appealing solution but is challenging as crucial structures are closely related to the tricuspid valve, and intracardiac devices pose further challenges to device delivery and implantation.

\section{KEY POINTS}

Preprocedural multimodality imaging is essential to identify the appropriate device and to ensure procedural success.

Transcatheter tricuspid valve devices can be classified based on the mechanism of action.

To date, the MitraClip in the tricuspid position (TriClip) is the most utilized device for tricuspid valve repair. Modifications to the Triclip and Pascal device may improve applicability and outcomes.

Transcatheter tricuspid valve interventions appear to be associated with improvement in patient quality of life.

\section{INTRODUCTION}

Primary tricuspid regurgitation (TR) occurs as a result of an anatomically abnormal tricuspid valve. Trace or mild TR is common even in anatomically normallooking valves and has no pathological implications. Certain etiologies such as rheumatic heart disease, prolapse, congenital disease (Ebstein anomaly), infective endocarditis, blunt wall trauma, endomyo-

All authors reported no financial interests or relationships that pose a potential conflict of interest with this article.

doi:10.3949/ccjm.87.s1.01 cardial biopsy-related trauma, and intra-annular right ventricular (RV) pacemaker or implantable cardiac defibrillator leads may result in more significant primary TR. However, it is important to note that close to $80 \%$ of TR cases are "functional" rather than primary.

Functional TR occurs secondary to annular dilation and leaflet tethering as a result of RV remodeling from either volume or pressure overload. ${ }^{1}$ The prevalence of functional TR in the United States is 1.6 million..$^{2-4}$ Such RV remodeling and resulting TR frequently occur as a complication of left-sided valvular disease, with mitral valve disease being the most common culprit. Severe TR is associated with poor prognosis independent of age and biventricular function. ${ }^{5}$ Early studies in the 1960s suggested that treatment of left-sided valvular pathology (particularly mitral) may reverse pulmonary hypertension and therefore TR. However, more contemporary literature reveals that this process is gradual and often unpredictable. ${ }^{6}$

Currently, surgical techniques are the mainstay of treatment for progressive or severe functional TR. However, with the advent and success of transcath-

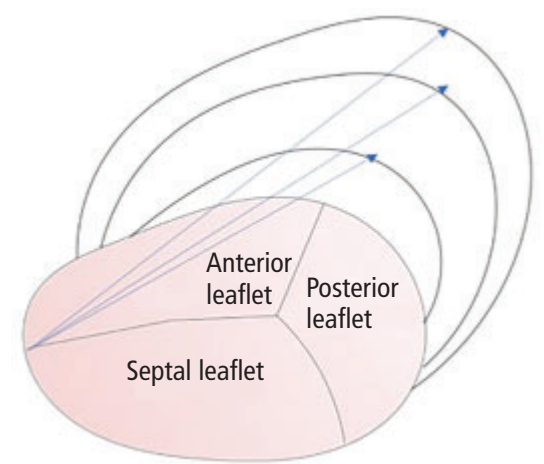

Figure 1. Schematic representation of the anatomy of the tricuspid annulus. The arrows represent annular dilation resulting in an increased anteroposterior diameter in functional tricuspid regurgitation. 
eter techniques for severe aortic stenosis and mitral regurgitation, there is newfound interest in creating safe and effective methods for minimally invasive management of functional TR.

\section{ANATOMY, PATHOPHYSIOLOGY}

Located between the right atrium and the RV, the tricuspid valve is slightly more apical than the mitral valve and consists of an annulus, leaflets, papillary muscles, and chordae tendinae (Figure 1).?

The tricuspid valve is oriented at a 45-degree angle to the sagittal plane facing anterolaterally and inferiorly toward the left side. The annulus of the tricuspid valve is a nonplanar structure with a distinct bimodal or saddle-shaped pattern having 2 high points (oriented superiorly toward the right atrium) and 2 low points (oriented inferiorly toward the RV). The tricuspid annular area on 3-dimensional (3D) echocardiography has been estimated as $9.72 \pm 2.08 \mathrm{~cm}^{2}$ in normal individuals. RV or annular dilation and tethering of the leaflets are the 2 main pathophysiologic mechanisms for the development of functional TR. While this is mostly secondary to left-sided disease, it may also be associated with isolated RV disease or pulmonary hypertension. The TR that develops through these mechanisms leads to further RV dilation and dysfunction and more tricuspid annular dilation and tethering, thereby progressively worsening the existing TR. This vicious cycle perpetuates TR and forms an integral part of the pathophysiology of severe TR. The increase in right-sided volumes and pressures impedes left ventricular relaxation and ejection, with resultant diastolic and sometimes systolic dysfunction. ${ }^{8,9}$

Anatomically, in patients with functional TR, the annulus is larger, flatter, and more circular thereby altering the saddle shape of a normal valve. The dilation of the tricus-

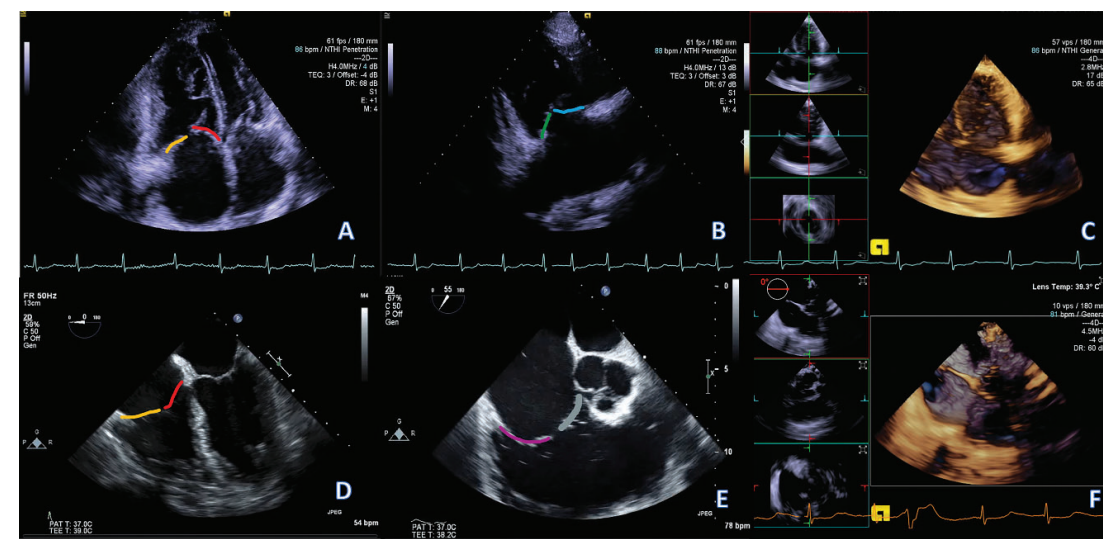

Figure 2. (A-C) Transthoracic echocardiography (TTE) views and (D-F) transesophageal echocardiography (TEE) views of the tricuspid valve (TV). (A) TTE 4-chamber view: The septal leaflet is shown in red. The other leaflet (orange) could be the anterior leaflet (if probe is angled anteriorly and the aortic valve is brought into view, ie, 5-chamber view) or the posterior leaflet (if probe is angled posteriorly and coronary sinus brought into view). (B) TTE RV inflow view: The anterior leaflet is shown in blue. The other leaflet (in green) could be the posterior leaflet or the septal leaflet. (C) TTE 3D focused on the tricuspid valve. Three orthogonal planes centered on the TV are cross-referenced (inlets on the left), allowing easier identification of the different leaflets. (D) TEE 4-chamber view: As in the TTE 4-chamber view, the septal leaflet (in red) is identified, and the other leaflet (orange) could be either the anterior or posterior. (E) TEE RV inflow view: The posterior leaflet is shown in purple, the other leaflet (in grey) could be either the anterior or septal leaflet. (F) TEE 3D focused on the tricuspid valve. As in the 3D TTE, 3 orthogonal planes are cross-referenced. The different leaflets are easier to identify.

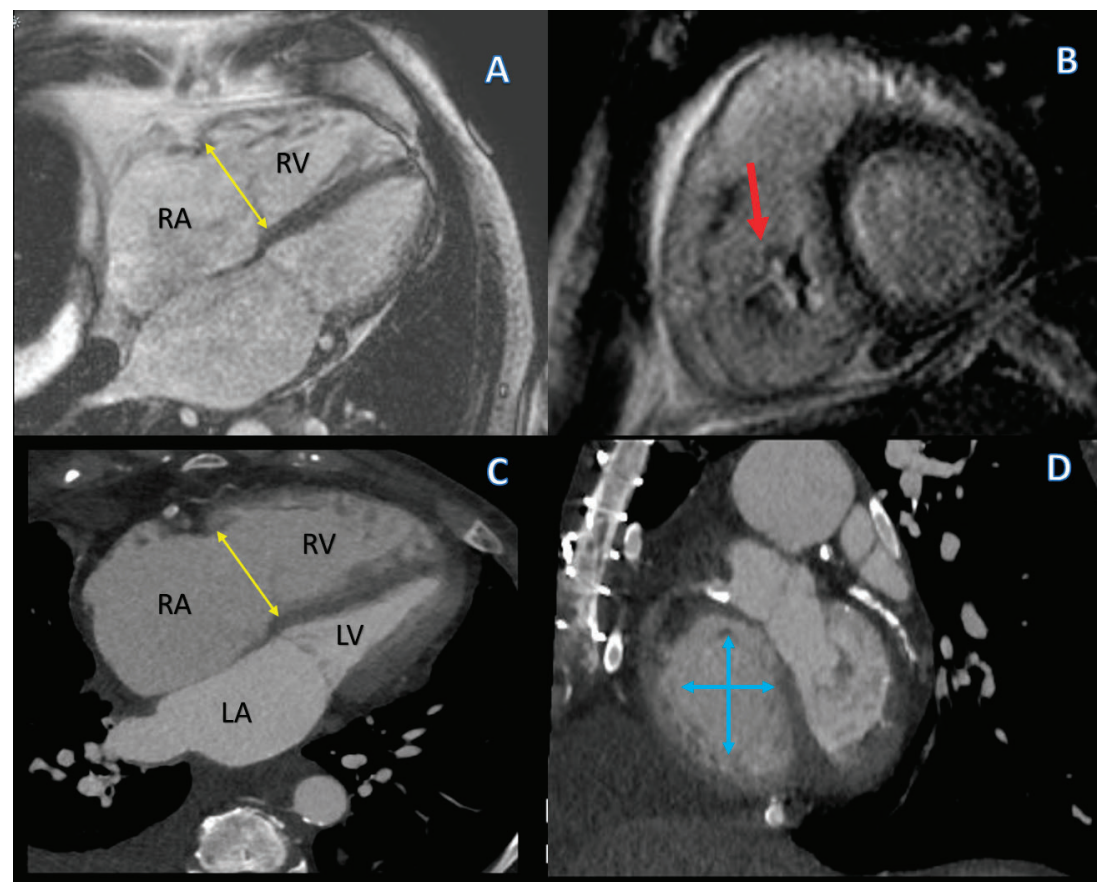

Figure 3. (A and B) Steady-state free precession magnetic resonance images in a 4-chamber and short-axis orientation, respectively. (A) Severely dilated tricuspid annulus (double arrow in yellow). The arrow in D points to a large area of central regurgitation (flow dephasing) caused by a lack of leaflet coaptation secondary to severe annular dilation. (C) Corresponding computed tomography image in a 4-chamber orientation also demonstrating an enlarged annulus (double arrow in yellow). The annular enlargement is better appreciated on the short-axis view (D, blue arrows). 
TABLE 1

\section{Staging of functional tricuspid regurgitation}

\begin{tabular}{|c|c|c|c|c|c|}
\hline & Stage 1 & Stage 2 & Stage 3 & Stage 4 & Stage 5 \\
\hline Symptoms & None & None $^{a}$ & None-vague $^{a}$ & $\begin{array}{l}\text { Current or previous } \\
\text { episodes of RHF }\end{array}$ & $\begin{array}{l}\text { Overt RHF and/or end- } \\
\text { organ damage due to } \\
\text { chronic RV volume } \\
\text { overload }^{\text {b }}\end{array}$ \\
\hline TR grade & $<$ Moderate & $>$ Moderate & Severe & Severe & Torrential \\
\hline Annular remodeling & Normal & $\begin{array}{l}\text { Normal or mildly } \\
\text { remodeled }\end{array}$ & Present & Moderate-severe & Severe \\
\hline Leaflet coaptation & Normal & Mildly abnormal & Abnormal & Coaptation gap & Large coaptation gap \\
\hline Tethering & None & $\begin{array}{l}\text { None or mildly abnormal } \\
(<8 \mathrm{~mm})\end{array}$ & $\begin{array}{l}\text { Abnormal } \\
\text { (usually < } 8 \mathrm{~mm} \text { ) }\end{array}$ & $\begin{array}{l}\text { Significantly abnormal } \\
\text { with varying degree } \\
\text { of tethering }\end{array}$ & $\begin{array}{l}\text { Significantly abnormal } \\
\text { (usually }>8 \mathrm{~mm} \text { ) }\end{array}$ \\
\hline $\begin{array}{l}\text { RV function and } \\
\text { remodeling }\end{array}$ & Normal & $\begin{array}{l}\text { Normal function } \\
\text { Absent or mild } \\
\text { remodeling }\end{array}$ & $\begin{array}{l}\text { Mild RV dysfunction } \\
\text { and/or remodeling }\end{array}$ & $\begin{array}{l}>\text { Moderate dysfunction } \\
\text { and remodeling }\end{array}$ & $\begin{array}{l}\text { Severe RV dysfunction } \\
\text { and remodeling }\end{array}$ \\
\hline Medical treatment & $\begin{array}{l}\text { No treatment but regular } \\
\text { clinical and echo follow- } \\
\text { up in patients with high } \\
\text { likelihood of developing } \\
\text { TR progression }\end{array}$ & $\begin{array}{l}\text { None or low-dose } \\
\text { diuretics }\end{array}$ & Diuretics & $\begin{array}{l}\text { Moderate to high-dose } \\
\text { diuretics and/or } \\
\text { requirement for IV } \\
\text { diuretics }\end{array}$ & $\begin{array}{l}\text { Multiple admissions for } \\
\text { RHF: Frequent need for } \\
\text { IV diuretics and/or } \\
\text { high-dose combination } \\
\text { diuretics }\end{array}$ \\
\hline Surgical treatment & No & $\begin{array}{l}\text { Consider TV surgery } \\
\text { (preferably repair) at } \\
\text { time of left-sided } \\
\text { surgery }\end{array}$ & $\begin{array}{l}\text { TV surgery (preferably } \\
\text { repair) at time of left- } \\
\text { sided surgery. Isolated } \\
\text { TV surgery (preferably } \\
\text { repair) in presence of } \\
\text { symptoms or progressive } \\
\text { RV remodeling and } \\
\text { comorbidities. }\end{array}$ & $\begin{array}{l}\text { Isolated TV surgery } \\
\text { (repair or replacement) } \\
\text { either isolated or at } \\
\text { time of left-sided } \\
\text { surgery in the absence } \\
\text { of severe pulmonary } \\
\text { hypertension and severe } \\
\text { comorbidities. High risk } \\
\text { of perioperative RV } \\
\text { dysfunction. }\end{array}$ & $\begin{array}{l}\text { Prohibitive intra- and } \\
\text { perioperative risk }\end{array}$ \\
\hline $\begin{array}{l}\text { Percutaneous } \\
\text { treatment }\end{array}$ & No & $\begin{array}{l}\text { Potential future target for } \\
\text { percutaneous options as } \\
\text { minimally invasive option } \\
\text { could change natural } \\
\text { history with minimal risk }\end{array}$ & $\begin{array}{l}\text { Potential candidates for } \\
\text { isolated TR surgery who } \\
\text { could be enrolled in } \\
\text { upcoming IDE RCTs }\end{array}$ & $\begin{array}{l}\text { Current group of patients } \\
\text { being treated in EFS if } \\
\text { high-risk for surgery. May } \\
\text { require combination of } \\
\text { annuloplasty and leaflet } \\
\text { device or TVR. }\end{array}$ & $\begin{array}{l}\text { Prohibitive risk and } \\
\text { potentially futile. } \\
\text { (Palliative procedures can } \\
\text { be considered in highly } \\
\text { selected patients.) }\end{array}$ \\
\hline
\end{tabular}

Although this staging scheme implies linear progression of the disease, in fact there may be patients with little tethering and RV remodeling but with severe TR secondary to severe right atrial dilatation, such as patients with idiopathic functional tricuspid regurgitation.

${ }^{a}$ Consider exercise test to evaluate functional capacity objectively.

${ }^{b}$ Multidisciplinary evaluation may be needed.

$\mathrm{EFS}$ = early feasibility studies; IDE = investigational device exemption; IV = intravenous; $\mathrm{RCT}=$ randomized controlled trial; $\mathrm{RHF}=$ right heart failure; $\mathrm{RV}=$ right ventricular; $\mathrm{TR}=$ tricuspid regurgitation; TV = tricuspid valve; TVR = tricuspid valve replacement

Source: Repinted with permission from Latib A, Grigioni F, Hahn RT. Tricuspid regurgitation: what is the real clinical impact and how often should it be treated? Eurolntervention 2018:14(AB):AB101-AB111.

pid annulus in functional TR is not symmetric. It has been shown that the anteroposterior distance increases by approximately $80 \%$, whereas the medio- lateral distance increases by only $34 \%$. This is because of a greater dilation along the free-wall aspect of the annulus (Figure 1).5,10,11 
TABLE 2

Echocardiographic grading of tricuspid regurgitation

\begin{tabular}{|c|c|c|c|c|c|}
\hline & Mild & Moderate & Severe & Massive & Torrential \\
\hline Central jet area & $<5 \mathrm{~cm}^{2}$ & $5-10 \mathrm{~cm}^{2}$ & $>10 \mathrm{~cm}^{2}$ & & \\
\hline Vena contracta (biplane) & $<3 \mathrm{~mm}$ & $3-6.9 \mathrm{~mm}$ & $7-13 \mathrm{~mm}$ & $14-20 \mathrm{~mm}$ & $\geq 21 \mathrm{~mm}$ \\
\hline EROA (PISA) & $<20 \mathrm{~mm}^{2}$ & $20-39 \mathrm{~mm}^{2}$ & $40-59 \mathrm{~mm}^{2}$ & $60-79 \mathrm{~mm}^{2}$ & $\geq 80 \mathrm{~mm}^{2}$ \\
\hline Vena contracta width & Not defined & $<0.70 \mathrm{~cm}$ & $>0.70 \mathrm{~cm}$ & & \\
\hline $\begin{array}{l}\text { Continuous wave jet } \\
\text { density and contour }\end{array}$ & Soft and parabolic & Dense and variable & $\begin{array}{l}\text { Dense, triangular } \\
\text { with an early peak }\end{array}$ & & \\
\hline Hepatic vein flow & Systolic dominance & Systolic blunting & Systolic reversal & & \\
\hline $\begin{array}{l}\text { Cardiac chambers } \\
\text { and IVC }\end{array}$ & $\begin{array}{c}\text { Normal size of } \\
\text { RA/RV/IVC }\end{array}$ & $\begin{array}{l}\text { No RV enlargement, } \\
\text { no or mild RA } \\
\text { enlargement, no or } \\
\text { mild IVC enlargement } \\
\text { with respirophasic } \\
\text { variation. } \\
\text { Normal RA pressure. }\end{array}$ & $\begin{array}{l}\text { RV/RA/IVC dilated } \\
\text { with decreased IVC } \\
\text { respirophasic variation. } \\
\text { Elevated RV pressure. } \\
\text { Diastolic intraventricular } \\
\text { septum flattening. } \\
\text { Reduced RV systolic } \\
\text { function in late phase. }\end{array}$ & & \\
\hline $\begin{array}{l}\text { 3D VCA or quantitative } \\
\text { EROA }\end{array}$ & & & $75-94 \mathrm{~mm}^{2}$ & $95-114 \mathrm{~mm}^{2}$ & $\geq 115 \mathrm{~mm}^{2}$ \\
\hline
\end{tabular}

3D VCA = three-dimensional vena contracta area; EROA = effective regurgitant orifice area; IVC = inferior vena cava; PISA = proximal isovelocity surface area; RA = right atrium; $\mathrm{RV}=$ right ventricle

Source: Data from references 1 and 12 .

\section{IMAGING GUIDELINES AND CHALLENGES}

TR requires multimodality imaging with $2 \mathrm{D}$ transthoracic echocardiography (TTE), 3D TTE, computed tomography (CT), and magnetic resonance imaging (MRI). While TTE and transesophageal echocardiography (TEE) are excellent at visualizing the tricuspid valve leaflets, CT and MRI are superior for accurate assessment of the tricuspid annulus geometry (Figures 2 and 3 ).

The first step to imaging the tricuspid valve is invariably 2D TTE. TTE can distinguish the etiology of TR, quantify its severity, and determine the annular dimensions. Some argue that the traditional classification of TR has limitations and the definition of severe TR is broad, thus a new classification has been proposed: mild, moderate, severe, massive, and torrential. ${ }^{12}$ Better classification of TR can potentially help clinicians identify patients who would benefit from transcatheter valve therapies. Similarly, a staging system has also been proposed for functional TR (Table 1) based on annular dilation, RV function, remodeling, TR severity, leaflet coaptation, and right-sided heart failure. ${ }^{13}$

Significant annular dilation on TTE is defined as diastolic diameter greater than $40 \mathrm{~mm}$ or greater than $21 \mathrm{~mm} / \mathrm{m}^{2}$. Simultaneous assessment of all 3 leaflets can be challenging; thus, different projections are useful (long-axis RV inflow, short-axis at the aortic valve, apical 4-chamber view, and subcostal views). ${ }^{10}$ Despite this, the designation of individual leaflets of the tricuspid valve should be done with caution unless all 3 leaflets can be seen simultaneously. Real-time 3D TTE proves to be useful in situations where this is not possible and allows, through its ability to obtain a short-axis view of the tricuspid valve, simultaneous visualization of all 3 leaflets moving during the cardiac cycle. It also allows visualization of their commissures and attachment to the tricuspid annulus. $8,9,14,15$ DD TTE can also be used to assess RV volumes; however, wherever available, cardiac MRI is the gold standard for assessing RV function and volumes. ${ }^{16}$ The American College of Cardiology/American Heart Association (ACC/AHA) guidelines recommend 3D TTE or MRI for evaluation of RV systolic function and RV volumes in patients with severe TR and suboptimal TTE (Class IIb, level of evidence C). CT offers indepth assessment of various dimensions relevant to 
TABLE 3

Guidelines for the management of functional tricuspid regurgitation

\section{American College of Cardiology/}

American Heart Association (2014)

- Tricuspid valve surgery is recommended for patients with severe tricuspid regurgitation (stages $C$ and $D$ ) undergoing leftsided valve surgery (Class I, level of evidence C).

- Current guidelines provide for tricuspid valve repair in patients with mild, moderate, or greater functional tricuspid regurgitation at the time of left-sided surgery with either tricuspid annular dilation or prior evidence of right heart failure (Class Ila, level of evidence B).

- Tricuspid valve repair may be considered for patients with moderate functional tricuspid regurgitation and pulmonary hypertension at the time of left-sided surgery (Class Ilb, level of evidence C).

- Reoperation for isolated tricuspid valve repair or replacement may be considered for persistent symptoms due to severe tricuspid regurgitation (stage D) in patients who have undergone previous left-sided valve surgery and who do not have severe pulmonary hypertension or significant right ventricular systolic dysfunction (Class Ilb, level of evidence C).
European Society of Cardiology (2017) ${ }^{20}$

- Surgery is indicated in patients with severe secondary tricuspid regurgitation undergoing left-sided surgery (Class I, level of evidence C).

- Surgery is indicated in patients with mild or moderate secondary tricuspid regurgitation with a dilated annulus ( $\geq 40 \mathrm{~mm}$ or $>21 \mathrm{~mm} / \mathrm{m}^{2}$ by 2-dimensional transthoracic echocardiography) undergoing left-sided surgery (Class Ila, level of evidence C).

- Surgery may be considered in patients undergoing left-sided surgery with mild or moderate secondary tricuspid regurgitation even in the absence of annular dilation when previous rightsided heart failure has been documented (Class Ilb, level of evidence C).

- After previous left-sided surgery and in the absence of recurrent left-sided valve dysfunction, surgery should be considered in patients with severe tricuspid regurgitation who are symptomatic or have progressive right ventricular dilation/dysfunction, in the absence of severe left ventricular/right ventricular dysfunction or pulmonary vascular disease/hypertension (Class Ila, level of evidence C). the tricuspid valve. This includes the dimensions of the RV, tricuspid valve annulus, and the annular distance from the RV apex. The venous anatomy and dimensions of the subclavian and axillary veins can guide access-site selection. The appropriate fluoroscopic angles for valve deployment can be derived from the CT. ${ }^{17}$ CT can also detect the course of the right coronary artery to the tricuspid annulus, and a course of $2 \mathrm{~mm}$ or less is considered high risk, which is a common finding in about $40 \%$ of patients with severe TR. ${ }^{18,19}$

\section{MANAGEMENT OF FUNCTIONAL TR}

Based on the 2014 ACC/AHA guidelines for valvular heart disease, grading of TR is done based on the central jet area, vena contracta width, continuous jet density and contour, and hepatic vein flow. Table 2 details the stages of TR based on these guidelines.

The guidelines recommend the use of diuretics in severe TR and signs of right-sided heart failure (Class IIa, level of evidence C). Medical therapies to reduce elevated pulmonary artery pressures or pulmonary vascular resistance or both are also recommended in severe functional TR (Class IIb, level of evidence
C, D). Table 3 displays a comparison of ACC/AHA guidelines (2014) and the European Society of Cardiology (2017) guidelines for surgical management of functional TR. ${ }^{1,20}$

\section{Patient selection}

Timely referral to a tertiary center is essential to achieve an optimal result after transcatheter tricuspid valve intervention. Functional TR is a common sequela of previous or current severe left-sided heart disease. The concept that surgical or percutaneous management of left-sided disease leads to spontaneous resolution of TR is a misconception. Concomitant treatment of TR and left-sided disease should always be considered during the index procedure. From the surgical literature, some of the predictors for recurrence of TR are tethering distance greater than $76 \mathrm{~mm}$, mitral valve replacement, pulmonary artery pressure of over $90 \mathrm{~mm} \mathrm{Hg}$, severe RV impairment, left ventricular dysfunction and advanced left ventricular remodeling, intracardiac devices, and suture annuloplasty. ${ }^{21-26}$ Patients with severe pulmonary hypertension and RV dysfunction do not tolerate a precipitous reduction in TR and can develop acute afterload mismatch and decompensation. ${ }^{27-29}$ 


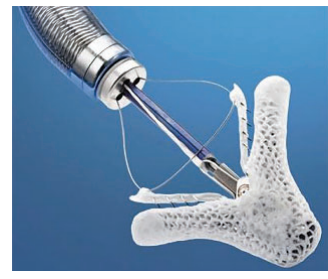

Figure 4. MitraClip.
All the factors mentioned above should be taken into consideration and the severity of TR should not be the primary reason for referral. Multiple staging systems have been proposed recently based on annular dilation, RV function, remodeling, TR severity, leaflet coaptation, and right-sided heart failure. ${ }^{13,30,31}$ Stages 4 and 5 as listed in Table 1 are not suitable for percutaneous transcatheter tricuspid valve management.

\section{Percutaneous tricuspid interventions: Devices and outcomes}

Use of transcatheter approaches for the treatment of severe aortic stenosis and mitral regurgitation has led to growing interest in adopting these techniques for severe functional TR. However, challenges to the tricuspid edge-to-edge repair include the trileaflet nature of tricuspid valve, wide malcoaptation gaps, higher chordal density, and fragility of the leaflet and annular tissues. Additionally, the proximity to the conduction system, right coronary artery, and coronary sinus potentially predispose to procedural complications..$^{32,33}$ However, despite these difficulties, there are several reasons to develop and advance novel methods of minimally invasive, percutaneous TR treatment. Medical treatment is restricted to the use of diuretics and can only partially address the symptoms, ${ }^{3}$ and TR is associated with poor prognosis both in isolated disease and when associated with left-sided pathology. It is also important to note that patients with TR may have less benefit from percutaneous procedures for mitral regurgitation. ${ }^{34,35}$

Several devices and strategies are being evaluated for the treatment of functional TR. These can be broadly classified by mechanism into leaflet approximation devices, annuloplasty devices, transcatheter tricuspid valve implantation, and caval valve implantation.

Leaflet approximation device. Sixty-four patients from 10 international centers were treated with the MitraClip (Abbott Vascular) for TR. Functional TR was present in $88 \%$ of patients. Results showed significant improvements in echocardiographic and functional parameters without any procedural adverse events with the use of the MitraClip device (Figure 4). It is interesting to note that patients who had a combined mitral and tricuspid MitraClip procedure did not have a significant increase in 6-minute walk distance at 30 days. However, there was a similar echocardiographic improvement in patients undergoing tricuspid clipping alone and those undergoing combined mitral and tricuspid clipping. ${ }^{36}$

The multicenter international TriValve (Transcatheter Tricuspid Valve Therapies) registry reported 1-year outcomes after edge-to-edge repair in 249 patients with severe TR. ${ }^{37}$ Nearly $90 \%$ of the cohort had functional TR and over half the population underwent concomitant treatment of tricuspid and mitral regurgitation. The mean age of the cohort was 77 and the mean European System for Cardiac Operative Risk Evaluation II score was 6.4\%. Procedural success was achieved in $77 \%$ of the patients (TR reduction to grade $\leq 2+$ ). At 12 months in nearly $70 \%$ of the patients there was sustained improvement in TR severity and New York Heart Association functional class $(\leq \mathrm{II})$. Death due to any cause was $20 \%$. The risk factors for procedural failure were the absence of central or anteroseptal TR jet location, effective regurgitant orifice area greater than or equal to $0.70 \mathrm{~cm}^{2}$, tricuspid coaptation gap greater than $0.65 \mathrm{~cm}$, and tenting area greater than $3.15 \mathrm{~cm}^{2} .^{37}$

The TRILUMINATE trial was a single-arm study of 85 patients with severe functional TR. ${ }^{2}$ No periprocedural deaths, myocardial infarctions, or strokes occurred. At 6 months, all-cause mortality was reported in 5\% (4 of 84) of patients and the rate of major bleeding was $11 \%$ (9 of 84). Single leaflet device attachment was seen in $7 \%$ of patients (5 of 72 ) and tricuspid valve stenosis was noted in $9 \%$ of patients (6 of 65).

The PASCAL system (Edwards Lifesciences) consists of a $10-\mathrm{mm}$ central spacer that blocks the regurgitant orifice. It attaches to the leaflets with 2 paddles and was first used in an 82-year-old woman with secondary TR and advanced right-sided heart failure. ${ }^{38}$ Two devices were implanted and the patient was discharged at 72 hours. At 1-month follow-up there was a resolution of ascites, and the dose of diuretics was lowered, which was associated with improved quality of life and 6-minute walk distance. The Edwards CLASP TR EFS (NCT03745313) study is evaluating the safety and efficacy of the PASCAL system in patients with severe symptomatic functional or degenerative TR.

Annuloplasty systems. Annuloplasty devices recreate surgical techniques and address the primary pathophysiologic mechanism of TR, annular dilation. All annular-based devices require sufficient annular tissue for anchoring and may be prone to dehiscence if tissue quality is poor or excessive force is applied. Therefore, 


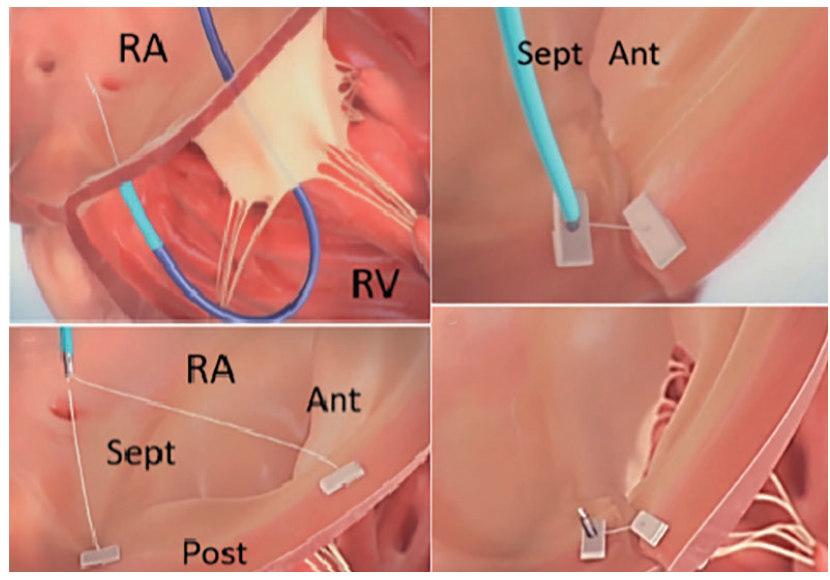

Figure 5. TriAlign system.

Ant $=$ anterior; Post = posterior; $\mathrm{RA}=$ right atrium; RV = right ventricle; Sept $=$ septal

Source: SCOUT study video from HeartValveSurgery.com

they may have limited effectiveness in patients with advanced RV disease and excessive tethering. ${ }^{39}$

The TriCinch system (4Tech Cardio Ltd.) is a percutaneous device designed for tricuspid remodeling, using a transfemoral fixation of a stainless-steel corkscrew into the anteroposterior tricuspid valve annulus. The corkscrew is connected through a Dacron band to a self-expanding Nitinol stent. By pulling the system towards the inferior vena cava, the anchoring corkscrew remodels the anteroposterior annulus, and the tension is maintained by fixation of the stent in the inferior vena cava. The first use of this device was reported in 2015 for the treatment of functional TR in a 72-year-old woman with right-sided heart failure and repeated decompensations. The patient reportedly had good functional status at 6-month follow-up..$^{40}$ The TriCinch Coil System was also performed with deliberate creation of pneumopericardium to guarantee the appropriate advancement of the device in a woman age 81 with severe functional TR. ${ }^{41}$ The PREVENT trial (Percutaneous Treatment of Tricuspid Valve Regurgitation With the TriCinch System) reported a procedural success rate of $94 \%$ in 18 patients ( $\geq$ 1 -grade reduction of TR). ${ }^{42}$ Two patients developed pericardial tamponade periprocedurally, and leaflet device detachment was noted in 4 patients. Significant improvement in 6-minute walk distance and quality of life was also noted. The safety and efficacy of the TriCinch System is currently being assessed in clinical trials (NCT03294200 and NCT03632967).

Another novel method of reducing functional TR is via plication of the tricuspid annulus using the TriAlign system (Mitralign Inc.) (Figure 5).
This system consists of a deflectable guide catheter introduced using a trans-jugular approach to position a wire catheter on the ventricular side of the tricuspid annulus, and then to introduce an insulated radiofrequency wire across the annulus. Thereafter, a pledgeted suture is delivered (using a catheter over the radiofrequency wire) and the process is repeated to insert a second pledget. The sutures are then plicated, leaving behind a bicuspid tricuspid valve with reduced annular dimensions and a regurgitant orifice. Recently, 30-day results from the SCOUT trial (Percutaneous Tricuspid Valve Annuloplasty System for Symptomatic Chronic Functional Tricuspid Regurgitation) were published using this procedure. In a cohort of 15 patients, they showed that there was $80 \%$ success without the need for re-intervention. ${ }^{43}$ The SCOUT II trial, an open-label nonrandomized clinical study, is currently recruiting patients with evidence of functional TR secondary to annular dilation (NCT03225612).

An exciting new development has been the Cardioband (ValtechCardio), which mimics open-heart annuloplasty for TR. It is a transcatheter annuloplasty system designed to implant a Dacron surgical-like adjustable band with a sutureless technique under echocardiographic and fluoroscopic guidance. The device is delivered via the transfemoral approach and is secured with 17 anchors on the atrial side of the anterior and tricuspid annulus. The first reported use in humans was published in early 2017 in a patient with functional TR and annular dilation who underwent the procedure successfully. The TRI-REPAIR study consisted of 30 patients undergoing Cardioband for moderate to severe functional TR. ${ }^{44}$ The average age of participants was 75 and most were women. Procedural success was $100 \%$, with a substantial decrease in annular septolateral diameter, effective regurgitant orifice area, and vena contracta width at 6 months. Similar results were reported by the Cardioband TR EFS Investigators in 22 patients ${ }^{45}$ (NCT03382457). The cohort consisted of mostly women (77\%) with a mean age of 78. Atrial fibrillation and flutter were common comorbidities, with a $96 \%$ prevalence rate, and the procedural success rate was $95 \%$. Complications included 1 right-sided coronary artery constriction, and 7 patients suffered a major bleeding event. There was no cardiovascular mortality, myocardial infarction, or stroke.

Another device in the investigation phase for tricuspid repair is the minimally invasive annuloplasty (MIA) technology (Micro Interventional Devices, Inc.). Two patients in Lithuania received this device 
with no intraoperative complications, based on media reports. The Study of Transcatheter Tricuspid Annular Repair (STTAR) is a multicenter safety and performance study being conducted in Europe to evaluate the use of this device. ${ }^{46}$

A new device under development is the Millipede system (Millipede Inc.), which is an adjustable, semirigid ring attached to the annulus by rotational anchors positioned at defined intervals. The device has a zigzag appearance like the top of a crown, with the anchors at the lowest points and a collar around the hinge points at the crests. The annular reduction is then accomplished by repositioning the collars further down the crest, effectively reducing the distance between the anchors. ${ }^{47}$ The pledget-assisted suture tricuspid annuloplasty (PASTA) device mirrors the Hetzer double-orifice suture procedure. ${ }^{48}$ The first in human experience resulted in annular dehiscence of the device 2 days after its insertion and this device potentially should be not be used in large friable annuli. ${ }^{48}$

Transcatheter tricuspid valve implantation. The Gate valve (NaviGate Cardiac Structures Inc.) is an atrioventricular valved stent that has been developed for the treatment of TR (Figure 6). The first reported use in humans of this catheter-guided tricuspid atrioventricular valved stent was at Cleveland Clinic in a 64-year-old woman with multiple comorbidities including end-stage renal disease and multiple prior admissions for right-sided heart failure. The tricuspid annulus measured $50 \mathrm{~mm} \times 40 \mathrm{~mm}$ on a focused $4 \mathrm{D}$ CT study. The patient tolerated the implantation well and was transferred to the ICU. Although she had a prolonged hospital course, she was discharged on postoperative day 29. The predischarge TTE for this patient showed moderate to severe RV dysfunction and mild to moderate TR, and paravalvular leak. The second patient was a 78-year-old man with significant cardiac history including coronary artery disease, previous myocardial infarction, atrial fibrillation, and 3 prior open-heart surgeries for coronary bypass, mitral valve repair, and 2 tricuspid valve repairs (annuloplasty ring $34 \mathrm{~mm}$ ). He had a progressive decline in functional capacity due to right-sided heart failure that was refractory to medical treatment. He was discharged successfully on postoperative day 7 , and predischarge TTE showed severe RV dysfunction and mild paravalvular TR. Both of these patients were deemed to be at prohibitive risk of open-heart surgery by a multi-disciplinary team. ${ }^{49}$

Caval aortic valve implantation (CAVI). Heterotopic tricuspid valve implantation is a potential option in patients with severe TR and significant venous con- gestion. The valve in this technique is inserted percutaneously into the inferior vena cava to protect the abdominal vasculature from elevated venous pressures and systolic backflow from severe TR. The upper valve segment protrudes into the right atrium, and the lower

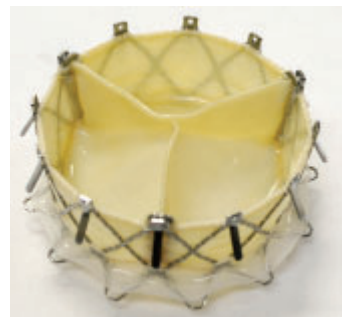

Figure 6. Gate valve. segment anchors to the inferior vena cava. The first reported experience with CAVI was reported by Lauten and colleagues in $2011 . .^{50}$ The valve implantation was successful, and the patient's functional capacity and heart failure symptoms improved. Right atrial volume overload and right atrial ventricularization are potential demerits of CAVI. ${ }^{51}$

The Treatment of Severe Secondary Tricuspid Regurgitation in Patients With Advance Heart Failure With Caval Vein Implantation of the Edwards Sapien XT Valve (TRICAVAL) trial consisted of 28 patients with severe symptomatic TR that were randomized to optimal medical therapy or Edwards Sapien XT valve implantation (NCT02387697)..$^{52}$ There was no difference noted in functional end points (6-minute walk test, RV function, hospitalizations, and quality of life) across the intervention and control arms. TRICAVAL was cancelled due to safety concerns. The Heterotopic Implantation of the Edwards-Sapien Transcatheter Aortic Valve in the Inferior Vena Cava for the Treatment of Severe Tricuspid Regurgitation (HOVER) (54) trial is currently evaluating the feasibility of this device ${ }^{53}$ (NCT02339974).

\section{Device-lead-induced TR}

Patients with device-lead-induced TR are a special subgroup. The reported incidence of lead-induced TR is as high as $45 \%^{54,55}$ and is linked to a poor prognosis. ${ }^{56}$ It has been postulated that this is caused by bulky leads and apical lead placement and that the leads also alter the RV geometry resulting in TR. ${ }^{57,58}$ TR can also be a result of leaflet perforation during lead placement. Other mechanisms include lead impingement or adherence and lead entrapment in the subvalvular apparatus of the tricuspid valve. Imaging can be challenging, and the severity of lead-induced TR is often underestimated. ${ }^{59}$ Newer imaging tools like calculation of regurgitant fractions and volumes based on 3D data sets could potentially overcome this challenge. Percutaneous transcatheter tricuspid interventions for lead-induced TR have been investigated using various devices including 
TABLE 4

Clinical trials investigating the use of new devices for tricuspid regurgitation

\begin{tabular}{|c|c|c|}
\hline Device & Clinical trial (NCT\#) & Primary endpoint \\
\hline $\begin{array}{l}\text { Tricuspid valve repair } \\
\text { system } \\
\text { (Abbott Medical Devices) }\end{array}$ & TRILUMINATE (NCT03227757) & $\begin{array}{l}\text { Tricuspid regurgitation reduction } \geq 1 \text { grade at } \\
1 \text { month } \\
\text { Composite of major adverse events at } 6 \text { months }\end{array}$ \\
\hline $\begin{array}{l}\text { PASCAL } \\
\text { (Edwards Lifesciences) }\end{array}$ & Edwards CLASP TR EFS (NCT03745313) & $\begin{array}{l}\text { Freedom from device or procedure-related adverse } \\
\text { events at } 1 \text { month }\end{array}$ \\
\hline \multirow[t]{2}{*}{$\begin{array}{l}\text { TriCinch system } \\
\text { (4Tech Cardio Ltd.) }\end{array}$} & PREVENT (NCT02098200) & $\begin{array}{l}\text { Safety: The percentage of participants with major } \\
\text { adverse events within } 30 \text { days of the procedure } \\
\text { Performance: The reduction in the degree of tricuspid } \\
\text { regurgitation measured immediately after the } \\
\text { procedure compared with baseline }\end{array}$ \\
\hline & $\begin{array}{l}\text { Clinical Trial Evaluation of the Percutaneous } \\
\text { 4Tech TriCinch Coil Tricuspid Valve Repair } \\
\text { System (NCT03294200) }\end{array}$ & All-cause mortality at 1 month \\
\hline $\begin{array}{l}\text { TriAlign } \\
\text { (Mitralign Inc.) }\end{array}$ & PTVAS (SCOUT-II) (NCT03225612) & Incidence of all-cause mortality at 30 days \\
\hline \multirow[t]{2}{*}{$\begin{array}{l}\text { Cardioband } \\
\text { (ValtechCardio) }\end{array}$} & TRI-REPAIR (NCT02981953) & $\begin{array}{l}\text { The overall rate of major serious adverse events } \\
\text { and serious adverse device effects at } 30 \text { days. } \\
\text { Successful access, deployment and positioning of the } \\
\text { Cardioband device and septolateral dimension } \\
\text { reduction intraprocedurally. Change in septolateral } \\
\text { dimension at } 30 \text { days. }\end{array}$ \\
\hline & $\begin{array}{l}\text { Edwards Cardioband Tricuspid Valve Reconstruction } \\
\text { System Early Feasibility Study (NCT03382457) }\end{array}$ & $\begin{array}{l}\text { Freedom from device or procedure-related adverse } \\
\text { events at } 30 \text { days. }\end{array}$ \\
\hline $\begin{array}{l}\text { MIA } \\
\text { (Micro Interventional } \\
\text { Devices Inc.) }\end{array}$ & STTAR (NCT03692598) & $\begin{array}{l}\text { Safety: Major adverse event at } 1 \text { month } \\
\text { Performance: The technical success rate of MIA } \\
\text { implant and reduction in the valve area }\end{array}$ \\
\hline
\end{tabular}

MIA = minimally invasive annuloplasty; PREVENT = Percutaneous Treatment of Tricuspid Valve Regurgitation With the TriCinch System; PTVAS = Performance of the Trialign Percutaneous Tricuspid Valve Annuloplasty System; TRILUMINATE = Clinical Trial to Evaluate Cardiovascular Outcomes In Patients Treated With the Tricuspid Valve Repair System; TRI-REPAIR = Tricuspid Regurgitation Repair With Cardioband Transcatheter System; STTAR = Study of Transcatheter Tricuspid Annular Repair

MitraClip, FORMA, TriCinch, Trialign, Cardioband, NaviGate, and CAVI. ${ }^{54}$ There is a risk of lead damage after device implantation and potentially impedes future lead extraction in case of lead endocarditis. ${ }^{60}$

\section{FUTURE TRIALS}

Several clinical trials of new devices for TR are currently under way (Table 4). To date, clinical trials have been done in patients with advanced stages of functional TR and there is an absence of a standard definition of clinical and imaging outcomes. Ideal trial design should include patients without RV dysfunction, remodeling, and right-sided heart failure that are randomized to surgical management or percutaneous intervention. The lack of specific clinical symptoms relevant to tricuspid valve disease and heavy reliance on quantitative assessment of TR, annular dilation, and RV size and function as imaging end points pose significant challenges for device approval. Important exclusion criteria should include severe pulmonary hypertension, severe RV failure, and other significant comorbidities (frailty, advanced kidney disease, liver dysfunction, severe lung disease). Another consideration could be given to a prospective registry of concomitant percutaneous mitral and tricuspid intervention for severe functional mitral regurgitation. Long-term preservation of RV function and preventing TR progression after tricuspid intervention could be demonstrated in such a cohort. 


\section{CONCLUSION}

Functional TR is a common valvular heart disease that is often overlooked and is linked to a poor prognosis. There are numerous percutaneous and minimally invasive options under different stages of investigation. The published data so far on percutaneous therapies demonstrate promising results in the form of a reasonable reduction in TR along with substantial improvement in the quality of life. The transcatheter device technology is currently evolving for the tricuspid valve. The evidence base in this intervention is growing rapidly; however, it is far behind its aortic counterpart. ${ }^{61,62}$ To improve the existing technology, it is imperative to understand tricuspid valve anatomy using multimodality imaging to identify patients early and prevent irreversible RV failure. Patient selection based on anatomy for the appropriate device technology (ie, coaptation vs annuloplasty vs replacement) is imperative. Improved device technology best matched to patient factors is likely to increase the array of options available to patients for TR.

\section{REFERENCES}

1. Nishimura RA, Otto CM, Bonow RO, et al; American Heart Association; American College of Cardiology. 2014 AHAVACC guideline for the management of patients with valvular heart disease: a report of the American College of Cardiology/American Heart Association Task Force on practice guidelines. J Thorac Cardiovasc Surg 2014; 148:e1e132. doi.org/10.1016/j.jtcvs.2014.05.014

2. Nickenig G, Weber M, Lurz P, et al. Transcatheter edge-to-edge repair for reduction of tricuspid regurgitation: 6-month outcomes of the TRILUMINATE single-arm study. Lancet 2019; 394(10213):2002-2011. doi:10.1016/S0140-6736(19)32600-5

3. Rodés-Cabau J, Taramasso M, O'Gara PT. Diagnosis and treatment of tricuspid valve disease: current and future perspectives. Lancet 2016; 388(10058):2431-2442. doi:10.1016/S0140-6736(16)00740-6

4. Topilsky Y, Maltais S, Medina Inojosa J, et al. Burden of tricuspid regurgitation in patients diagnosed in the community setting. JACC Cardiovasc Imaging 2019; 12(3):433-442. doi:10.1016/j.jcmg.2018.06.014

5. Chopra HK, Nanda NC, Fan P, et al. Can two-dimensional echocardiography and Doppler color flow mapping identify the need for tricuspid valve repair? J Am Coll Cardiol 1989; 14(5):1266-1274. doi:10.1016/0735-1097(89)90426-9

6. Agarwal S, Tuzcu EM, Rodriguez ER, Tan CD, Rodriguez LL, Kapadia SR. Interventional cardiology perspective of functional tricuspid regurgitation. Circ Cardiovasc Interv 2009; 2(6):565-573. doi:10.1161/ CIRCINTERVENTIONS.109.878983

7. Rogers JH, Bolling SF. The tricuspid valve: current perspective and evolving management of tricuspid regurgitation. Circulation 2009; 119(20):2718-2725. doi:10.1161/CIRCULATIONAHA. 108.842773

8. Badano LP, Agricola E, Perez de Isla L, Gianfagna P, Zamorano JL. Evaluation of the tricuspid valve morphology and function by transthoracic real-time three-dimensional echocardiography. Eur J Echocardiogr 2009; 10(4):477-484. doi 0.1093/ejechocard/jep044

9. Badano LP, Muraru D, Enriquez-Sarano M. Assessment of functional tricuspid regurgitation. Eur Heart J 2013; 34(25):1875-1885. doi:10.1093/eurheartj/ehs474

10. Tornos Mas P, Rodríguez-Palomares JF, Antunes MJ. Secondary tricuspid valve regurgitation: a forgotten entity. Heart 2015; 101(22):18401848. doi:10.1136/heartjnl-2014-307252

11. Barlow JB. Aspects of tricuspid valve disease, heart failure and the "restriction-dilatation syndrome." Rev Port Cardiol 1995; 14(12):9911004. pmid:8562116

12. Hahn RT, Zamorano JL. The need for a new tricuspid regurgitation grading scheme. Eur Heart J Cardiovasc Imaging 2017; 18(12):13421343. doi:10.1093/ehjci/jex139

13. Latib A, Grigioni F, Hahn RT. Tricuspid regurgitation: what is the real clinical impact and how often should it be treated? Eurolntervention 2018; 14(AB):AB101-AB111. doi:10.4244/EIJ-D-18-00533

14. Lancellotti $P$, Tribouilloy $C$, Hagendorff $A$, et al; on behalf of the Scientific Document Committee of the European Association of Cardiovascular Imaging. Recommendations for the echocardiographic assessment of native valvular regurgitation: an executive summary from the European Association of Cardiovascular Imaging. Eur Heart J Cardiovasc Imaging 2013; 14(7):611-644. doi:10.1093/ehjci/jet105

15. Muraru D, Badano LP, Sarais C, Solda E, Iliceto S. Evaluation of tricuspid valve morphology and function by transthoracic three-dimensional echocardiography. Curr Cardiol Rep 2011; 13(3):242-249. doi:10.1007/ s11886-011-0176-3

16. Park J-B, Lee S-P, Lee J-H, et al. Quantification of right ventricular volume and function using single-beat three-dimensional echocardiography: a validation study with cardiac magnetic resonance. J Am Soc Echocardiogr 2016; 29(5):392-401. doi:10.1016/j.echo.2016.01.010

17. Pozzoli A, Maisano F, Kuwata S, et al. Fluoroscopic anatomy of the tricuspid valve: Implications for Transcatheter procedures. Int J Cardiol 2017; 244:119-120. doi:10.1016/j.ijcard.2017.06.048

18. van Rosendael PJ, Kamperidis V, Kong WK, et al. Computed tomography for planning transcatheter tricuspid valve therapy. Eur Heart J 2017; 38(9):665-674. doi:10.1093/eurheartj/ehw499

19. Taramasso M, Pozzoli A, Basso C, et al. Compare and contrast tricuspid and mitral valve anatomy: interventional perspectives for transcatheter tricuspid valve therapies. Eurolntervention 2018; 13(16):18891898. doi:10.4244/EIJ-D-17-00704

20. Baumgartner H, Falk V, Bax JJ, et al; on behalf of the Task Force for the Management of Valvular Heart Disease of the European Society of Cardiology (ESC) and the European Association for Cardio-Thoracic Surgery (EACTS). 2017 ESC/EACTS guidelines for the management of valvular heart disease. Eur Heart J 2017; 38(36):2739-2791. doi:10.1093/ eurheartj/ehx391

21. McCarthy PM, Bhudia SK, Rajeswaran J, et al. Tricuspid valve repair: durability and risk factors for failure. J Thorac Cardiovasc Surg 2004; 127(3):674-685. doi:10.1016/j.jtcvs.2003.11.019

22. Fukuda S, Song JM, Gillinov AM, et al. Tricuspid valve tethering predicts residual tricuspid regurgitation after tricuspid annuloplasty. Circulation 2005; 111(8):975-979. doi:10.1161/01.CIR.0000156449.49998.51

23. Zack CJ, Fender EA, Chandrashekar P, et al. National trends and outcomes in isolated tricuspid valve surgery. J Am Coll Cardiol 2017; 70(24):2953-2960. doi:10.1016/j.jacc.2017.10.039

24. Navia JL, Nowicki ER, Blackstone EH, et al. Surgical management of secondary tricuspid valve regurgitation: annulus, commissure, or leaflet procedure? J Thorac Cardiovasc Surg 2010; 139(6):1473-1482.e5. doi:10.1016/j.jtcvs.2010.02.046

25. Navia JL, Kapadia S, Elgharably H, et al. First-in-human implantations of the NaviGate bioprosthesis in a severely dilated tricuspid annulus and in a failed tricuspid annuloplasty ring. Circ Cardiovasc Interv 2017; 10(12):e005840. doi:10.1161/CIRCINTERVENTIONS.117.005840

26. Asmarats L, Puri R, Latib A, Navia JL, Rodés-Cabau J. Transcatheter tricuspid valve interventions: Landscape, challenges, and future directions. J Am Coll Cardiol 2018; 71(25):2935-2956. doi:10.1016/j.jacc.2018.04.031

27. Jang JY, Heo R, Lee $\mathbf{S}$, et al. Comparison of results of tricuspid valve repair versus replacement for severe functional tricuspid regurgitation. Am J Cardiol 2017; 119(6):905-910. doi:10.1016/j.amjcard.2016.11.071

28. Yiu KH, Wong A, Pu L, et al. Prognostic value of preoperative right ventricular geometry and tricuspid valve tethering area in patients undergoing tricuspid annuloplasty. Circulation 2014; 129(1):87-92. doi:10.1161/CIRCULATIONAHA.113.003811

29. Krishnaswamy A, Navia J, Kapadia SR. Transcatheter tricuspid valve replacement. Interv Cardiol Clin 2018; 7(1):65-70. doi:10.1016/j. iccl.2017.08.009

30. Asmarats L, Puri R, Latib A, Navia JL, Rodés-Cabau J. Transcatheter tricuspid valve interventions: landscape, challenges, and future 
directions. J Am Coll Cardiol 2018; 71(25):2935-2956. doi:10.1016/j. jacc.2018.04.031

31. Dreyfus GD, Martin RP, Chan KM, Dulguerov F, Alexandrescu C. Functional tricuspid regurgitation: a need to revise our understanding. $J$ Am Coll Cardiol 2015; 65(21):2331-2336. doi:10.1016/j.jacc.2015.04.011

32. Rogers JH. Functional tricuspid regurgitation: percutaneous therapies needed. JACC Cardiovasc Interv 2015; 8(3):492-494. doi:10.1016/j. jcin.2014.11.013

33. Buzzatti N, De Bonis M, Moat N. Anatomy of the tricuspid valve, pathophysiology of functional tricuspid regurgitation, and implications for percutaneous therapies. Interv Cardiol Clin 2018; 7(1):1-11. doi:10.1016/j.iccl.2017.08.005

34. Schueler R, Öztürk C, Sinning J-M, et al. Impact of baseline tricuspid regurgitation on long-term clinical outcomes and survival after interventional edge-to-edge repair for mitral regurgitation. Clin Res Cardiol 2017; 106(5):350-358. doi:10.1007/s00392-016-1062-1

35. Koelling TM, Aaronson KD, Cody RJ, Bach DS, Armstrong WF. Prognostic significance of mitral regurgitation and tricuspid regurgitation in patients with left ventricular systolic dysfunction. Am Heart J 2002; 144(3):524-529. doi:10.1067/mhj.2002.123575

36. Nickenig G, Kowalski M, Hausleiter J, et al. Transcatheter treatment of severe tricuspid regurgitation with the edge-to-edge MitraClip technique. Circulation 2017; 135(19):1802-1814. doi:10.1161/ CIRCULATIONAHA.116.024848

37. Mehr M, Taramasso M, Besler C, et al. 1-year outcomes after edge-toedge valve repair for symptomatic tricuspid regurgitation: results from the TriValve Registry. JACC Cardiovasc Interv 2019; 12(15):1451-1461. doi:10.1016/j.jcin.2019.04.019

38. Fam NP, Ho EC, Zahrani M, Samargandy S, Connelly KA. Transcatheter tricuspid valve repair with the PASCAL system. JACC Cardiovasc Interv 2018; 11(4):407-408. doi:10.1016/j.jcin.2017.12.004

39. Mangieri A, Montalto C, Pagnesi M, et al. Mechanism and implications of the tricuspid regurgitation: from the pathophysiology to the current and future therapeutic options. Circ Cardiovasc Interv 2017; 10(7):e005043. doi:10.1161/CIRCINTERVENTIONS.117.005043

40. Latib A, Agricola E, Pozzoli A, et al. First-in-man implantation of a tricuspid annular remodeling device for functional tricuspid regurgitation. JACC Cardiovasc Interv 2015; 8(13):e211-e214.

41. Gheorghe L, Swaans M, Denti P, Rensing B, Van der Heyden J. Transcatheter tricuspid valve repair with a novel cinching system. JACC Cardiovasc Interv 2018; 11(24):e199-e201. doi:10.1016/j.jcin.2018.09.019

42. Nietlispach F. Tricinch for TR: technique and outcomes. Presented at: Transcatheter Valve Therapies (TVT 2017), a Cardiovascular Research Foundation meeting; June 16, 2017; Chicago, IL.

43. Hahn RT, Meduri CU, Davidson CJ, et al. Early feasibility study of a transcatheter tricuspid valve annuloplasty: SCOUT trial 30-day results. J Am Coll Cardiol 2017; 69(14):1795-1806. doi:10.1016/j.jacc.2017.01.054

44. Nickenig G, Weber M, Schueler R, et al. 6-Month outcomes of tricuspid valve reconstruction for patients with severe tricuspid regurgitation. $J$ Am Coll Cardiol 2019; 73(15):1905-1915. doi:10.1016/j.jacc.2019.01.062

45. Gray W; for the Cardioband TR EFS Investigators. Results from the early feasibility study of cardioband tricuspid system for functional tricuspid regurgitation. Presented at: Transcatheter Valve Therapies (TVT 2017), a Cardiovascular Research Foundation meeting; September 24-28, 2019; San Francisco, CA. TCT-93.

46. Dash D, Li L. Intravascular ultrasound guided percutaneous coronary intervention for chronic total occlusion. Curr Cardiol Rev 2015; 11(4):323-317. doi:10.2174/1573403X11666150909105827

47. Hahn RT. Current transcatheter devices to treat functional tricuspid regurgitation with discussion of issues relevant to clinical trial design. Ann Cardiothorac Surg 2017; 6(3):240-247. doi:10.21037/acs.2017.03.10

48. Khan JM, Rogers T, Schenke WH, et al. Transcatheter pledget-assisted suture tricuspid annuloplasty (PASTA) to create a double-orifice valve. Catheter Cardiovasc Interv 2018; 92(3):E175-E184. doi:10.1002/ccd.27531
49. Navia JL, Kapadia S, Elgharably H, et al. First-in-human implantations of the navigate bioprosthesis in a severely dilated tricuspid annulus and in a failed tricuspid annuloplasty ring. Circ Cardiovasc Interv 2017; 10(12):e005840. doi:10.1161/CIRCINTERVENTIONS.117.005840

50. Lauten A, Ferrari M, Hekmat K, et al. Heterotopic transcatheter tricuspid valve implantation: first-in-man application of a novel approach to tricuspid regurgitation. Eur Heart J 2011; 32(10):1207-1213. doi:10.1093/eurheartj/ehr028

51. Lauten A, Figulla HR, Unbehaun A, et al. Interventional treatment of severe tricuspid regurgitation: early clinical experience in a multicenter, observational, first-in-man study. Circ Cardiovasc Interv 2018; 11(2):e006061. doi:10.1161/CIRCINTERVENTIONS.117.006061

52. Dreger H, Mattig I, Hewing B, et al. Treatment of severe TRIcuspid regurgitation in patients with advanced heart failure with CAval vein implantation of the Edwards Sapien XT VALve (TRICAVAL): a controlled prospective randomized trial [published online ahead of print, 2020 Jan 14]. Eurolntervention 2020; EIJ-D-19-00901. doi:10.4244/ EIJ-D-19-00901

53. O'Neill BP, Wheatley G, Bashir R, et al. Study design and rationale of the heterotopic implantation of the Edwards-Sapien XT transcatheter valve in the inferior VEna cava for the treatment of severe tricuspid regurgitation (HOVER) trial. Catheter Cardiovasc Interv 2016; 88(2):287-293. doi:10.1002/ccd.26530

54. Addetia K, Harb SC, Hahn RT, Kapadia S, Lang RM. Cardiac implantable electronic device lead-induced tricuspid regurgitation. JACC Cardiovasc Imaging 2019; 12(4):622-636. doi:10.1016/j.jcmg.2018.09.028

55. Fanari Z, Hammami S, Hammami MB, Hammami S, Shuraih M. The effects of right ventricular apical pacing with transvenous pacemaker and implantable cardioverter defibrillator on mitral and tricuspid regurgitation. J Electrocardiol 2015; 48(5):791-797. doi:10.1016/j. jelectrocard.2015.07.002

56. Delling FN, Hassan ZK, Piatkowski G, et al. Tricuspid regurgitation and mortality in patients with transvenous permanent pacemaker leads. Am J Cardiol 2016; 117(6):988-992. doi:10.1016/j.amjcard.2015.12.038

57. Zhang HX, Qian J, Hou FQ, Liu YN, Mao JH. Comparison of right ventricular apex and right ventricular outflow tract septum pacing in the elderly with normal left ventricular ejection fraction: long-term follow-up. Kardiol Pol 2012; 70(11):1130-1139. pmid:23180520

58. Vaturi M, Kusniec J, Shapira Y, et al. Right ventricular pacing increases tricuspid regurgitation grade regardless of the mechanical interference to the valve by the electrode. Eur J Echocardiogr 2010; 11(6):550553. doi:10.1093/ejechocard/jeq018

59. Lin G, Nishimura RA, Connolly HM, Dearani JA, Sundt TM 3rd, Hayes DL. Severe symptomatic tricuspid valve regurgitation due to permanent pacemaker or implantable cardioverter-defibrillator leads. J Am Coll Cardiol 2005; 45(10):1672-1675. doi:10.1016/j.jacc.2005.02.037

60. McElhinney DB, Cabalka AK, Aboulhosn JA, et al. Transcatheter tricuspid valve-in-valve implantation for the treatment of dysfunctional surgical bioprosthetic valves: an international, multicenter registry study. Circulation 2016; 133(16):1582-1593. doi:10.1161/ CIRCULATIONAHA.115.019353

61. Reiff C, Gurevich S, Bertog S, Sorajja P, Kelly R, Garcia S. Validation of STS/ACC TVT-TAVR score in veterans undergoing transcatheter aortic valve replacement. J Invasive Cardiol 2018; 30(12):447-451. pmid:30218556

62. Blanke P, Weir-McCall JR, Achenbach S, et al. Computed tomography imaging in the context of transcatheter aortic valve implantation (TAVI)/ transcatheter aortic valve replacement (TAVR): an expert consensus document of the Society of Cardiovascular Computed Tomography. J Cardiovasc Comput Tomogr 2019; 13(1):1-20. doi:10.1016/j.jcct.2018.11.008

Correspondence: Samir Kapadia, MD, Department of Cardiovascular Medicine, Heart, Vascular, and Thoracic Institute, J2-3, Cleveland Clinic, 9500 Euclid Avenue, Cleveland, OH 44195; kapadis@ccf.org 